\title{
EL MANTENIMIENTO DE LA REFERENCIA ANAFÓRICA EN EL DISCURSO NARRATIVO TRADICIONAL EN LENGUA MALECU
}

\author{
Haakon Stensrud Krohn
}

\begin{abstract}
RESUMEN
En este artículo se analizan, desde la perspectiva de la gramática funcional, las diferentes estrategias que se emplean para expresar las referencias anafóricas en malecu. Los análisis se llevan a cabo tanto de manera cuantitativa como cualitativa, y se muestran la relación que existe entre la identificabilidad del referente y la estrategia utilizada por el hablante, así como las funciones de los pronombres.

Palabras clave: Malecu, referencia, distancia anafórica, sintaxis, análisis del discurso.
\end{abstract}

\section{ABSTRACT}

This paper analyzes, within the functionalist framework, the different strategies used to express anaphoric references in Maleku. The analyses are carried out both quantitatively and qualitatively, and show the relation between the referent's identifiability and the strategy used by the speaker, as well as the functions of the pronouns.

Key words: Maleku, reference, anaphoric distance, syntax, discourse analysis.

\section{Introducción}

El malecu, también llamado guatuso, es una lengua chibchense hablada por los malecus en el cantón de Guatuso en el norte de Costa Rica. Es una lengua de marcación de casos ergativo-absolutiva. Este sistema se codifica en la conjugación de los verbos, de modo que existe una serie de prefijos para indicar la persona gramatical del absolutivo y otra para indicar la del ergativo (Constenla 1998: 69-73). Los prefijos verbales de persona son los siguientes: ${ }^{1}$

ML. Haakon Stensrud Krohn. Profesor. Escuela de Filología, Lingüística y Literatura. Universidad de Costa Rica Correo electrónico: hkrohn@gmail.com

Recepción: 21- 06- 2012

Aceptación: 06- 09- 2012 


\section{Cuadro 1. Los prefijos verbales de persona en malecu}

$\begin{array}{lll} & \text { Absolutivos } & \text { Ergativos } \\ 1^{\text {a }} \text { persona exclusiva } & \text { na- } & \text { rra- } \\ 1^{\text {a }} \text { persona inclusiva } & \text { ma- } & \text { ri- } \\ 2^{\text {a }} \text { persona } & \text { mi- } & \text { rrifa- } \\ 3^{\text {a }} \text { persona } & \text { i- } & \text { rri- }\end{array}$

Algunos de los prefijos presentan varios alomorfos (Constenla 1998: 70-73). El prefijo ergativo rrifa- (/ripa/) puede perder la /i/ en habla rápida y, además, la /a/ puede caer ante consonantes no labiales; si, en tal caso, la / $/$ / queda ante una consonante sorda, esta se convierte en [p]. Por lo tanto, este prefijo presenta los alomorfos [ripa] $\sim$ [rip] $\sim[$ rob $\sim$ [rip] $~$ [roa] [rp]. Los prefijos absolutivos que contienen una /i/ (mi- e $i$-) cambian esta vocal por una [a] cuando aparecen ante el prefijo ergativo $\mathrm{rra}^{-}$, como consecuencia de un fenómeno de armonía vocálica; de ahí que presenten los alomorfos $m a$ - ([ma]) y $a$ - ([a]), respectivamente.

Pueden aparecer sintagmas nominales o pronombres personales correferenciales a las series de prefijos. Estos elementos no llevan ninguna marcación morfológica de caso, por lo que la marcación morfológica de casos se da únicamente en los verbos. Por esta razón, Constenla afirma:

[L]os prefijos son los elementos que desempeñan las funciones de ergativo [y] absolutivo [...] Los sintagmas nominales de presencia facultativa con los cuales 'concuerdan' se consideran más bien elementos detalladores. (1998: 69-70) ${ }^{2}$

También existe una construcción alternativa llamada "orientación al ergativo". En esta construcción, el participante ergativo no es codificado mediante ningún prefijo verbal, sino por medio de un pronombre o un sintagma nominal en un sintagma posposicional con la posposición - $t$.

De acuerdo con Constenla (1998), la posición básica de todos los sintagmas nominales de la proposición verbal es a la izquierda de la forma verbal. Los pronombres siempre se colocan en dicha posición, mientras que las otras formas nominales detalladoras pueden desplazarse al lado derecho del verbo. Cuando ocurre un desplazamiento a la derecha, muchas veces el elemento nominal se duplica por medio de un tema nominal sustitutivo (más frecuentemente ní), que se coloca en la posición que sería la básica del elemento desplazado (a la izquierda de la forma verbal). Los pronombres personales son los siguientes:

$\begin{array}{ll}\text { Cuadro 2. Los pronombres personales en malecul } \\ 1^{\text {a }} \text { persona exclusiva singular } & \text { ton } \\ 1^{\text {a }} \text { persona exclusiva plural } & \text { toí } \\ 1^{\text {a }} \text { persona inclusiva (plural) } & \text { tótiquí } \\ 2^{\text {a }} \text { persona } & \text { pó }\end{array}$

En ningún trabajo hasta ahora se han presentado de manera específica los factores que determinan la aparición de los llamados sintagmas nominales detalladores en malecu. Constenla (1975: 284) argumenta que "los prefijos de remisión a objeto pueden funcionar como sustitutos de las formas nominales a las que remiten". Afirma que las "sustituciones" de los pronombres de primera y segunda persona son generales, y que el no sustituirlos tiene valor de énfasis o insistencia. Álvarez et al. (1979) no aportan más información sobre el asunto, y afirman simplemente que los pronombres y los sintagmas nominales a los que sustituyen los 
prefijos son optativos. De la misma manera, Constenla (1986: 120) sostiene que "el verbo puede aparecer sin el sintagma o sintagmas con los cuales concuerda", sin proponer condiciones que regulen el fenómeno. Constenla (1998) tampoco ofrece un análisis más profundo del tema, sino que se limita a clasificar las formas nominales detalladoras como "facultativas" y afirma que son empleadas solo para agregar detalle a la referencia de los prefijos verbales de persona. Por último, Quesada (2007: 71-72) presenta unos ejemplos del rama y del teribe, y asegura que sucede lo mismo en el malecu: las cláusulas con un sintagma nominal detallador se suelen emplear en la introducción del discurso, para dar énfasis o para reactivar participantes, mientras que los sintagmas nominales se omiten en contextos de continuidad topical.

En resumen, solo Quesada (2007) relaciona la aparición de las formas nominales detalladoras con la topicalidad y la continuidad anafórica, pero es evidente que esta afirmación está basada en observaciones, no en un análisis sistemático. También Constenla (1975) considera que el fenómeno depende de un factor pragmático y afirma que la aparición de los elementos detalladores de primera y segunda persona expresa énfasis o insistencia, explicación que no se vuelve a mencionar en los trabajos posteriores de este autor. En todos los demás trabajos, la aparición de dichos sintagmas es descrita como "facultativa", "optativa" o "no obligatoria".

Por lo tanto, aunque la gramática del malecu está exhaustivamente descrita a nivel de la cláusula, es evidente que es necesario describir su funcionamiento en unidades mayores, analizando las funciones gramaticales extra-clausales de la lengua, para llegar a entender el sistema de las referencias anafóricas. En este artículo se analiza dicho sistema tanto de manera cuantitativa como cualitativa. Se procura aportar datos importantes para dos perspectivas lingüísticas: la intralingüística y la interlingüística. En primer lugar, como se ha visto, se investiga un área de la gramática del malecu que es imprescindible conocer mejor si se espera llegar a entender las estructuras tanto a nivel de la cláusula como a nivel discursivo de manera más completa. En segundo lugar, servirá como aporte para los estudios comparativos que se enfocan en el mantenimiento de la referencia en distintos idiomas.

\section{Marco teórico}

La perspectiva teórica que se siguió en el presente trabajo es la de la gramática funcional, específicamente el funcionalismo tipológico, tal y como es presentado por Givón (2001a, 2001b). También se tomó en cuenta la teorización de otros autores que trabajan desde un marco funcionalista (Chafe 1994, Payne 1997).

El funcionalismo es una corriente lingüística empirista y se opone a teorías de carácter mentalista, como la gramática generativa. La idea fundamental del funcionalismo es que la relación entre la forma y el significado a nivel gramatical no es arbitraria, sino intencional; no obstante, el funcionalismo no niega la existencia de una arbitrariedad en la codificación de conceptos básicos por medio de palabras y sonidos (Givón 2001a: 4).

Las diferentes lenguas del mundo utilizan una serie de diferentes construcciones con elementos anafóricos que aseguran la coherencia del texto manteniendo la referencia de participantes previamente mencionados en el texto. Según Givón (2001a: 417-20), la construcción utilizada depende de la necesidad de especificar o explicitar el referente. En contextos de baja continuidad anafórica del referente, donde el oyente puede tener problemas para comprender cuál es el referente exacto de un elemento anafórico (comúnmente porque no ha sido mencionado a lo largo de varias cláusulas), es necesario que el hablante utilice una construcción que lo exprese de manera más explícita. Esta especificación la lleva a cabo el 
hablante para facilitarle la comprensión al oyente, pues para el hablante, desde luego, nunca hay duda de cuál es el referente. De esta manera, la codificación del referente refleja de manera icónica la continuidad del tópico.

Givón (1983) señala que hay cuatro factores principales que determinan la dificultad del oyente para identificar un participante:

a. La distancia referencial

b. La posible interferencia de otros participantes

c. La accesibilidad de información semántica

d. La accesibilidad de información temática

Este lingüista analiza solamente los dos primeros factores, ya que los otros dos son difíciles de medir. La distancia referencial, o distancia anafórica, es el número de cláusulas entre una referencia anafórica y la última referencia del mismo participante. Con "posible interferencia", Givón (1983: 14) se refiere a la presencia de otros participantes en el contexto precedente que pueden producir ambigüedad en cuanto a la identificación del referente que se desea mantener.

Chafe (1994) describe el mismo fenómeno destacando la distinción entre información dada, accesible y nueva: la información dada es la que el hablante supone que el oyente tiene presente en la conciencia, por el hecho de que ya ha sido mencionada en el presente discurso y se encuentra activada; la información accesible es la que el hablante supone que el oyente conoce, pero que se encuentra en un estado semiactivo, mientras que la información nueva es la que el hablante piensa que está activando en la conciencia del oyente. Este autor argumenta que probablemente la información dada se expresa de manera más atenuada, o menos explícita, en todas las lenguas del mundo, típicamente por medio de un pronombre átono o la elipsis.

La información nueva o accesible, por su lado, se suele expresar por medio de sintagmas nominales completos. Chafe (1994) afirma que los sintagmas nominales completos también se usan para expresar información dada en casos en los que se podría producir ambigüedad; es decir, cuando hay dos o más posibles referentes. Según este autor (1994: 79), el número de referentes que pueden estar activos al mismo tiempo es relativamente bajo, y cada referente tiene que ser mencionado continuamente para seguir en el estado activo.

La continuidad anafórica puede medirse por medio de la "distancia anafórica": cuantas más cláusulas hay entre un elemento anafórico y la última aparición de un elemento correferencial, mayor es la distancia anafórica y menor es la continuidad. Como señala Givón (2001a: 463), la distancia anafórica no es una medida directa de la accesibilidad mental de los referentes, pero ofrece una buena indicación al respecto.

Givón (2001a: 417) expone que existen cuatro estrategias gramaticales para expresar referencias anafóricas en inglés:

a. cero anafórico

b. pronombres anafóricos átonos

c. pronombres independientes tónicos

d. sintagmas nominales completos definidos 
Siguiendo al mismo autor, cabe destacar que esta lista representa una escala de continuidad referencial del contexto en el que se utilizan las estrategias mencionadas. Ariel denomina "escala de marcación de accesibilidad" (1990: 73) a este tipo de escala.

Es necesario recordar que dichas estrategias son las que presenta el inglés, y que no se puede esperar que otras lenguas se ajusten perfectamente a esta clasificación, ni que se tenga la misma distribución en todas las lenguas. Por lo tanto, es necesario investigar cómo se distribuyen las construcciones anafóricas en cada lengua específica. En cuanto a las estrategias anafóricas en español, Brucart (1999: 2800) afirma que el sintagma nominal que representa un argumento verbal puede omitirse si en "en el discurso inmediatamente previo" se ha hecho mención del referente y no hay "ningún otro referente más adecuado". El uso de los pronombres personales, por su lado, es descrito por Luján (1999: 1277) como una estrategia que normalmente expresa énfasis o contraste.

En lo que concierne a estudios de las estrategias anafóricas de otras lenguas chibchenses, cabe mencionar el estudio de Jara (2003) sobre el bribri, en el cual se muestra que el uso de pronombres es la estrategia más frecuente en dicho idioma, mientras que se utilizan estrategias más explícitas principalmente para introducir o reintroducir nuevos participantes. La anáfora cero también existe, pero aparece en muy pocos casos. Salas (1990), por su lado, señala que también en boruca el cero anafórico es muy poco frecuente y que los pronombres se emplean con alta frecuencia, aunque la estrategia léxica es la predominante.

\section{Corpus analizado}

El corpus analizado para el presente trabajo comprende diez narraciones tradicionales en malecu, específicamente las primeras diez de las publicadas en Constenla, Castro y Blanco (1993), libro que constituye una de las colecciones más extensas de narraciones en malecu, con once en total. El último texto incluido en dicho libro fue excluido del corpus porque consiste principalmente en una serie de mandamientos de los dioses en forma de cláusulas imperativas con pocos referentes recurrentes a lo largo del discurso, por lo que no resulta adecuado para un análisis del mantenimiento de la referencia discursiva. Todas las narraciones son clasificadas por Constenla dentro del género de pláticas tradicionales (marácunúca).

Puesto que las narraciones en malecu presentan varios rasgos que las distinguen del estilo conversacional, sobre todo el paralelismo (repetición de la misma idea) y la estructuración en versos y estrofas, es importante tener en cuenta que los resultados de la investigación pueden diferir considerablemente de los que se obtendrían con una investigación en la que se analicen discursos conversacionales en el mismo idioma.

En Constenla, Castro y Blanco (1993), las líneas (que muchas veces no corresponden a cláusulas) están enumeradas. Las referencias de los ejemplos tomados del corpus que se presentan en este trabajo incluyen el número de la página en la que se encuentra en el libro original y el número de línea, separados por punto y coma. Por ejemplo, Constenla, Castro y Blanco (1993: 72;104) significa la línea número 104 del corpus, la cual se encuentra en la página 72. Constenla, Castro y Blanco (1993: 111;1572-1573) se refiere a las líneas 1572-1573 del corpus, que se encuentran en la página 111 del libro.

Las traducciones libres al español de los ejemplos en malecu son, en la mayoría de los casos, las proporcionadas por Constenla. Sin embargo, en algunos casos se han modificado para reflejar el significado más literalmente con la intención de facilitar la comprensión de los ejemplos. 


\section{Elementos anafóricos en malecu}

Para emprender el análisis del corpus, es necesario primero considerar cuáles son los elementos anafóricos empleados en malecu. Como se mencionó, este idioma posee dos series de prefijos verbales de persona con valor anafórico. Los prefijos son obligatorios en el sentido de que, en una cláusula intransitiva, el verbo nunca puede aparecer sin un prefijo de la serie absolutiva y, en una cláusula sintácticamente transitiva, el verbo tiene que llevar prefijos de las dos series.

De acuerdo con Givón (2001a: 407-410), la concordancia verbal de persona es el resultado de la gramaticalización de pronombres anafóricos átonos, por lo que los prefijos verbales de persona en malecu provendrían de dos series de pronombres clíticos que con el tiempo fueron estabilizados en el verbo hasta convertirse en afijos de concordancia obligatorios. Esta teoría coincide con lo afirmado por Constenla (2008: 132-133), con respecto a que el malecu y varios otros idiomas chibchenses poseen prefijos verbales cuyo origen serían pronombres personales protochibchenses. Los prefijos han mantenido su función anafórica y, aunque se ha desarrollado una nueva serie de pronombres tónicos, estos últimos no han llegado a ser obligatorios. El orden respectivo fijo en el malecu, con el prefijo ergativo siempre más cerca de la raíz verbal que el absolutivo, indica que la gramaticalización debe haber tenido lugar en un periodo en el que el orden básico de los constituyentes de la cláusula era de absolutivo, ergativo y raíz verbal, respectivamente.

Una de las estrategias empleadas en malecu para referirse anafóricamente a un referente es mediante un prefijo verbal de persona sin otro elemento correferencial en la misma cláusula. Este tipo de construcción es el menos explícito. En todos los análisis, la realización cero del prefijo verbal de tercera persona de la serie absolutiva es tratada de la misma manera que los demás prefijos, ya que este es un alomorfo cuya aparición está condicionada morfosintácticamente. La serie absolutiva de prefijos no se utiliza solamente para conjugar verbos, sino que también aparece con sustantivos y posposiciones, por lo que cualquiera de estos elementos puede incluir referencias anafóricas expresadas por medio de prefijos de esta serie. El ejemplo 1, tomado de las narraciones incluidas en Constenla, Castro y Blanco (1993: 86;636), consiste en una cláusula en la que los prefijos de la serie absolutiva aparecen en diferentes tipos de sintagmas. El prefijo $i$ - en el verbo $i$-tó-ye así como el prefijo $i$ en el sintagma nominal $i$-úrifá son referencias del actante del evento, mientras que el sintagma posposicional já incluye un alomorfo cero del mismo prefijo que se refiere a la persona a la que acudía el actante. Todos estos tipos de referencias anafóricas fueron tomados en cuenta en los análisis.

(1) ta-cá i-úrjifá yu nenhca $\emptyset$-já i-tó-ye y-SUC 3-hija (3)-con como.aquel (3)-a 3-ir-MR "le llevaba a su hija"

Los llamados pronombres personales pueden aparecer como elementos correferenciales con los prefijos de persona dentro de la misma cláusula. En este trabajo se han incluido dentro de la clase de pronombres tanto la serie de pronombres de la primera y la segunda persona como todos los elementos que funcionan como sustitutos de sustantivos. El más frecuente de los últimos es ní. Otros elementos de este tipo con referencia a la tercera persona que se encontraron en el corpus fueron sarróqui 'eso', sárru 'ese', naí 'aquel', nenhca 'como aquel', 
nícaní 'mucho', ónha 'en cantidad inusitada' y enéque 'otro'. Lo que todos estos elementos tienen en común es que siempre necesitan un referente especificado, encuéntrese este fuera (referencia exofórica, en el caso de los elementos deícticos) o dentro (referencia endofórica) del discurso, para que el oyente pueda identificarlo, ya que aportan menos información semántica que los sustantivos.

La tercera estrategia que se tomó en cuenta es la de prefijo verbal de persona con un elemento correferencial semánticamente más explícito en la misma cláusula: un sintagma nominal completo (término que también abarca las cláusulas subordinadas).

En resumen, las tres estrategias de referencia anafórica principales en malecu que se tomaron en cuenta fueron las siguientes (con ejemplos correspondientes tomados del corpus): ${ }^{3}$

a. prefijo verbal sin otro elemento correferencial en la misma cláusula (ej. 2 y 3)

b. pronombre correferencial con un prefijo verbal (o alomorfo cero de prefijo verbal) en la misma cláusula (ej. 4 y 5)

c. sintagma nominal completo correferencial con un prefijo verbal (o alomorfo cero de prefijo verbal) en la misma cláusula (ej. 6 y 7 )

(2) ta-cá i-to-nh maráme

y-SUC 3-venir-MR PL

"y llegaron"

(Constenla, Castro y Blanco 1993: 68;37)

(3) ta-cá i-j i-p-teléle-nhé

y-SUC 3-sobre 3-AP-pisotear-MR

"y lo pisoteó"

(Constenla, Castro y Blanco 1993: 82;508)

(4) jué ní ní maráma Ø-punh

en.efecto 3 PL (3)-estar-(MR)

"en efecto, ellos existen"

(Constenla, Castro y Blanco 1993: 67;25)

(5) ta-cá epéme ní $\emptyset$-yu u-nhé focte-nh

y-SUC NEG 3 (3)-con (3)-andar-FORM poder-MR

"y no soportó estar con ella"

(Constenla, Castro y Blanco 1993: 70;112)

(6) chí tafá maráma Ø-tat

todo tigre PL (3)-morir-(MR)

"todos los tigres murieron"

(Constenla, Castro y Blanco 1993: 92;868)

(7) Aíqui rri-túje maráme i-carrcóra lh.

maíz (3)-3erg-cocinar PL.MR 3-muslo (3)-sobre

"Cocimaban maíz sobre los muslos."

(Constenla, Castro y Blanco 1993: 78;414) 


\section{Análisis cuantitativo}

Como se ha expuesto, Givón $(1983,2001$ a) señala que existe una estrecha conexión entre la accesibilidad de la información para el oyente y la estrategia utilizada por parte del hablante para expresar las referencias anafóricas. Si la escala de marcación de accesibilidad es aplicable también para el malecu, se mostraría que las diferentes construcciones utilizadas para expresar referencias anafóricas se emplean de acuerdo con la continuidad anafórica de su referente.

Se calculó la distancia anafórica promedio que presentan los referentes de cada una de las tres estrategias mencionadas, de tal manera que las cifras indicarían si la estrategia preferida por parte del hablante es condicionada por la supuesta accesibilidad en la memoria del oyente, y las tres estrategias se podrían ordenar en una jerarquía como la que presenta Givón (2001a) para el inglés. La distancia anafórica es el número de cláusulas desde la última aparición del mismo referente. Empleamos un máximo arbitrario de 20, igual que en Givón (1983: 443), ya que este autor afirma que el oyente normalmente no es capaz de identificar un referente a más distancia.

En el análisis es importante distinguir entre elementos anafóricos y no anafóricos; los elementos que introducen nuevos participantes en el discurso no son anafóricos y, por lo tanto, no se les asignó ninguna distancia anafórica. La primera aparición de un participante en un texto se considera la introducción de ese participante, y todas las subsiguientes menciones del mismo participante se cuentan como referencias anafóricas.

Los resultados de la medición de las distancias anafóricas promedios se presentan en el cuadro 3. Recuérdese que las tres construcciones son las siguientes: prefijo sin otro elemento correferencial en la misma cláusula, pronombre (normalmente correferencial con un prefijo verbal en la misma cláusula), y sintagma nominal completo (normalmente correferencial con un prefijo verbal en la misma cláusula). La distancia promedio de cada estrategia se detalla primero, y entre paréntesis se anota el número de casos registrados en el texto en cuestión. Los números en la primera fila corresponden a los textos del corpus. En la última columna se consignan los números totales de todo el corpus.

Cuadro 3. Distancias anafóricas promedios de las tres estrategias anafóricas en cada texto del corpus

\begin{tabular}{|l|l|l|l|l|l|l|l|l|l|l|l|}
\hline & 1 & 2 & 3 & 4 & 5 & 6 & 7 & 8 & 9 & 10 & Total \\
\hline Prefijo & $\begin{array}{l}1,88 \\
(60)\end{array}$ & $\begin{array}{l}1,73 \\
(167)\end{array}$ & $\begin{array}{l}1,12 \\
(34)\end{array}$ & $\begin{array}{l}1,53 \\
(95)\end{array}$ & $\begin{array}{l}1,66 \\
(80)\end{array}$ & $\begin{array}{l}1,92 \\
(74)\end{array}$ & $\begin{array}{l}2,17 \\
(179)\end{array}$ & $\begin{array}{l}2,28 \\
(105)\end{array}$ & $\begin{array}{l}2,59 \\
(112)\end{array}$ & $\begin{array}{l}2,27 \\
(112)\end{array}$ & $\begin{array}{l}1,99 \\
(1018)\end{array}$ \\
\hline Prefijo + pronombre & $\begin{array}{l}1,25 \\
(4)\end{array}$ & $\begin{array}{l}3,25 \\
(4)\end{array}$ & $\begin{array}{l}- \\
(0)\end{array}$ & $\begin{array}{l}5,00 \\
(4)\end{array}$ & $\begin{array}{l}1,60 \\
(5)\end{array}$ & $\begin{array}{l}4,75 \\
(8)\end{array}$ & $\begin{array}{l}10,5 \\
(2)\end{array}$ & $\begin{array}{l}1,00 \\
(1)\end{array}$ & $\begin{array}{l}3,75 \\
(4)\end{array}$ & $\begin{array}{l}2,13 \\
(8)\end{array}$ & $\begin{array}{l}3,45 \\
(40)\end{array}$ \\
\hline $\begin{array}{l}\text { Prefijo + } \\
\text { SN }\end{array}$ & $\begin{array}{l}12,50 \\
(8)\end{array}$ & $\begin{array}{l}4,95 \\
(44)\end{array}$ & $\begin{array}{l}1,33 \\
(3)\end{array}$ & $\begin{array}{l}4,43 \\
(44)\end{array}$ & $\begin{array}{l}5,20 \\
(10)\end{array}$ & $\begin{array}{l}3,23 \\
(35)\end{array}$ & $\begin{array}{l}5,00 \\
(20)\end{array}$ & $\begin{array}{l}6,05 \\
(20)\end{array}$ & $\begin{array}{l}5,59 \\
(22)\end{array}$ & $\begin{array}{l}2,00 \\
(12)\end{array}$ & $\begin{array}{l}4,82 \\
(218)\end{array}$ \\
\hline
\end{tabular}

Los resultados totales de las distancias anafóricas promedios son muy parecidos a las tendencias que describe Givón (2001a) para cada tipo de construcción. En los textos analizados en malecu, los prefijos sin otro elemento correferencial en la misma cláusula presentan la menor distancia anafórica promedio, de aproximadamente 2 cláusulas. Le sigue la estrategia que incluye un pronombre, cuya distancia anafórica promedio es un poco menor de 3,5 cláusulas. Por último, la estrategia con sintagma nominal completo tiende a emplearse en contextos de mayor distancia anafórica, con una distancia promedio de casi 5 cláusulas. Parece evidente que, para el hablante, un factor importante a la hora de escoger el tipo de construcción es el grado 
de accesibilidad del referente, tal como afirma Givón (2001a): Cuando la distancia de la última mención del mismo referente es mayor, se tiende a utilizar una estrategia más explícita.

La distancia anafórica promedio de la estrategia menos explícita en cada texto varía desde 1,12 (texto 3) hasta 2,59 (texto 9) cláusulas. Su distancia promedio total es de 1,99. La distancia anafórica promedio de las construcciones con sintagma nominal completo es claramente mayor que la de la estrategia menos explícita en todos los textos, salvo en el texto 10 , en el cual se presenta una distancia anafórica promedio de 2,00, un poco menor que la de la estrategia menos explícita $(2,27)$. Además, cabe mencionar que las construcciones que incluyen un sintagma nominal completo se emplean en la gran mayoría de los casos en los que se introduce un participante nuevo. En estos casos, la construcción no constituye una referencia anafórica.

La distancia anafórica promedio de las construcciones con pronombre varía mucho de un texto a otro; en algunos resulta ser la estrategia que presenta menor distancia anafórica (textos 1, 5 y 8), y en otros, su distancia anafórica es mayor que las construcciones que incluyen un sintagma nominal completo (textos 4, 6, 7 y 10). Por lo tanto, el uso de estas construcciones pareciera no seguir un patrón basado en la distancia anafórica, tomando en cuenta las variaciones que se presentan en cada texto, por lo que puede que su uso principalmente se deba a otros factores, una posibilidad en la que se profundizará en el análisis cualitativo.

Pese a que los resultados parecen concordar con la teoría de Givón (2001a), aparecen una serie de excepciones a la tendencia general a lo largo de los textos. Esto se evidencia en los resultados de los análisis de cada texto. Por ejemplo, en el texto 10, las expresiones de participantes que incluyen un sintagma nominal completo presentan menor distancia anafórica promedio que las que solo incluyen un prefijo. Lo que todos los números desviantes tienen en común es que se basan en muy pocas observaciones; en los textos en los que estas construcciones aparecen con más frecuencia, los resultados se ajustan más al promedio.

De todas formas, la existencia de tales excepciones nos sugiere que la accesibilidad del referente tal vez no sea el único factor que influye en la elección de estrategia. El fenómeno será analizado más adelante en el análisis cualitativo.

\section{Análisis cualitativo}

En este parte se presentan los resultados del análisis cualitativo del corpus. El análisis parte principalmente de los resultados de los análisis cuantitativos, los cuales se analizan de manera más detallada, pero también se tratan de explicar otros aspectos del sistema de mantenimiento de las referencias anafóricas en malecu.

\subsection{Introducción de nuevos participantes}

En la gran mayoría de los casos en los que se introducen nuevos participantes en el discurso, estos son expresados por medio de un sintagma nominal completo, lo cual era lo esperado. Por esta razón, no se ha considerado necesario investigar esta frecuencia de manera cuantitativa. El siguiente ejemplo (Constenla, Castro y Blanco 1993: 78;386-393) muestra cómo los nuevos referentes típicamente se introducen en el discurso en malecu mediante elementos léxicos:

(8) a. I-quí nícacáfa i-pu-nhé curíjurí, chí-fa curíjurí maráma,

3-decir cierta.vez 3-estar-MR mujer todo-ENF mujer PL

"Se dice que había mujeres, todas las mujeres," 
b. ta-cá epéme coré maráma cué palá a-nhé, y-SUC NEG (3)-de PL fuego pedazo (3)-ser-MR "y no tenían fuego"

c. ta-cá i-carrcóra j i-p-túje maráme. y-SUC 3-muslo (3)-sobre 3-AP-cocinar PL.MR "y cocinaban sobre sus muslos."

d. Ninhá-fa orróqui rri-túje maráme, así-ENF cosa (3)-3erg-cocinar PL.MR "Así cocinaban cosas,"

e. malacá ó yu tonh maráme, carne que (3)-con (3)-venir PL.MR "carne que traían,"

f. ta-cá ninhá-fa ní rri-túje maráme iyanh, y-SUC así-ENF este (3)-3erg-cocinar PL.MR yuca "y así cocinaban la yuca"

g. macháca rri-jué-ca maráma aj. chicha (3)-3erg-hacer-N PL (3)-para "para hacer chicha."

El participante más topical en esta narración, curíjurí maráma 'las mujeres', es introducido mediante un sintagma nominal completo (que se repite en la misma cláusula para subrayar que se trata de todas). En cada una de las cláusulas siguientes se introduce un nuevo referente en el discurso, todos por medio de un elemento léxico: cué palá 'el fuego' (8b), icarrcóra 'sus muslos' (8c), orróqui 'cosa' (8d), malacá 'carne' (8e), iyanh 'yuca' (8f) y macháca 'chicha' (8g).

Sin embargo, se registran algunos pocos casos en los que la referencia no se explicita semánticamente en la cláusula en la que se introduce. En el siguiente ejemplo (Constenla, Castro y Blanco 1993: 89;732-733), el referente no es explicitado en ningún momento, pero parece que acá se entiende que, con ayuda del contexto (por ejemplo la información de que vivían en el Lugar de la Voltea de Laureles), se habla de las personas:

(9) a. I-quí nícacáfa i-anh maráme, 3-decir cierta.vez (3)-ser PL.MR

"Se dice que cierta vez había (unas personas),"

b. $\quad$ ta-cá i-pu-cá maráma Pú Jalíji-ca Nhúti. y-SUC 3-estar-N PL Laurel (3)-voltear-N (3)-donde "y vivían en el Lugar de la Voltea de Laureles."

En ciertos otros casos, el referente se explicita algunas cláusulas después de su introducción, como en el ejemplo 10 (Constenla, Castro y Blanco 1993: 71;125-128), en el que Tócu maráma 'los dioses' es el participante ergativo en la primera cláusula, pero se explicita hasta en la cuarta. Tal vez, el hablante aquí se da cuenta de la posible ambigüedad que representa el uso no explícito de la tercera persona del plural (podría haberse referido por ejemplo a las personas y no a los dioses), por lo que decide especificar el referente después. 
(10) a. ta-cá ní rri-cuanh maráme Tóji lacá lha. y-SUC este (3)-3erg-ver PL.MR Sol tierra (3)-sobre "y vieron al Sol sobre la tierra."

b. I-quí nán i-quí chiúti i-nhá-nhe, 3-decir pues 3-decir blanco 3-como-SUST

"Se dice, pues, se dice que era semejante a los blancos,"

c. i-quí nán i-quí nícaní i-conh-ílha.

3-decir pues 3-decir mucho 3-boca-(3)-pelo

"se dice, pues, se dice que tenía mucha barba"

d. Ní yu a-cá ó Tócu maráma.

este (3)-con (3)-ser-N que dios PL

"Esto le sucedió con los dioses."

\subsection{Uso de sintagmas nominales completos}

\subsubsection{Función principal de los sintagmas nominales completos}

El uso de estrategias léxicas frente a estrategias menos explícitas para expresar referencias anafóricas parece estar condicionado por varios factores diferentes. Primeramente, buscaremos los principios más básicos que regulen el uso, y luego trataremos de explicar las excepciones a las tendencias generales. Las excepciones se pueden dividir en dos grupos: (1) sobre-codificación de la referencia (uso de una estrategia léxica donde se esperaría una estrategia no léxica) o (2) sub-codificación de la referencia (uso de una estrategia no léxica donde se esperaría una estrategia léxica). Los casos de introducción de referentes de manera no léxica que acabamos de ver en 3 y 4 son ejemplos de sub-codificación.

El análisis cuantitativo reveló que la estrategia anafórica empleada por parte del hablante está relacionada con la distancia anafórica del referente, es decir, la accesibilidad del referente en la memoria episódica del oyente. En el corpus analizado, la estrategia de un prefijo sin otro elemento correferencial presenta una distancia anafórica promedio de 1,99 cláusulas, y la de un prefijo con un pronombre correferencial es de 3,45 cláusulas. La estrategia de un prefijo con un sintagma nominal completo es la estrategia que presenta la mayor distancia promedio, de 4,82 cláusulas. La relación con la accesibilidad para el oyente se evidencia aun más si se toma en cuenta la gran cantidad de referentes nuevos (los cuales no son accesibles) que se introducen por medio de una estrategia léxica. Lo que queda por explicar es cuán accesibles tienen que ser los referentes para poderse expresar mediante una estrategia no léxica, y cuáles factores de los que reducen la facilidad de identificar el referente son los más frecuentes.

Después de haber analizado el corpus cualitativamente, el esquema general parece ser que una referencia no explícita se refiere a alguno de los últimos participantes mencionados en el discurso (los más topicales en cada momento), típicamente los dos últimos. Las estrategias léxicas parecen funcionar principalmente para indicar que se habla de un referente que no ha sido de los más topicales en las últimas cláusulas, como se verá en los ejemplos que siguen. 
El siguiente pasaje es tomado del texto 1 (Constenla, Castro y Blanco 1993: 67;9-22):

(11) a. Ta-cá juactené-fa ní co i-p-tóri-nhé ó Aóre Cha Có-nhe.

y-SUC primero-ENF este (3)-en (3)-AP-soñar-MR que Río.Muerte (3)-

Cabecera (3)-en-SUST

"Y primeramente soñó con La de la Cabecera del Aóre."

b. Ta-cá ilhá yája i-a-nhé,

y-SUC 3-hacia llegado 3-ser-MR

"Y luego llegó (ella),"

c. Aóre Cha Có-nhe yáj i-a-nhé ú co.

Río.Muerte (3)-Cabecera (3)-en-SUST llegado 3-ser-MR casa (3)-en

"La de la Cabecera del Aóre llegó a la casa."

d. Ta-cá rri-quí:

y-SUC (3)-3erg-decir

"Y le dijo:"

e. “Mírriní pó mi-tonh?”

de.dónde 2 2-venir-(MR)

"¿De dónde vienes?"

f. Ta-cá rri-quí:

y-SUC (3)-3erg-decir

"Y le dijo:"

g. 'Epéme jué ní curífa na-unhé-unhé,

NEG en.efecto este recientemente 1E-andar-IT

"'No por poco tiempo he existido,"

h. tá pó, ¿mírri mi-tonh?’

y 2 de.dónde 2-venir-(MR)

"y tú, ¿de dónde vienes?"”

i. Ta-cá rri-quí:

y-SUC (3)-3erg-decir

"Y le dijo:"

j. 'Epéme jué ní curífa na-unhéunh.'

NEG en.efecto este recientemente 1E-andar.iterativo

"No por poco tiempo he existido.",

k. Ta-cá ní maráma có i-p-tóri-nhé, y-SUC este PL (3)-en 3-AP-soñar-MR

"Y soñó con ellos,"

1. ó enéque atác acsufá maráma.

que otro motu.proprio (3)-existente PL

"los otros que existen por su propia voluntad." 
Aquí se ve cómo un nuevo participante, La de la Cabecera del Aóre, ${ }^{4}$ es introducido en el discurso mediante un sintagma nominal y se establece como tópico. El tópico principal en las cláusulas anteriores no incluidas en este ejemplo ha sido El de la Cabecera del Nharíne, puesto que ha sido el único argumento verbal en todas las cláusulas, y sigue siendo el participante absolutivo en 11a, donde se introduce La de la Cabecera del Aóre por medio de un sintagma posposicional. Ella se convierte en el tópico principal en 11b y 11c. En 11c se expresa otra vez de manera léxica para explicitar que ahora es La de la Cabecera del Aóre quien es el actante del verbo intransitivo y no El de la Cabecera del Nharíne como en las cláusulas previas.

A partir de este punto aparecen cláusulas transitivas, y los dos referentes más topicales siguen siendo los actantes de los eventos verbales. En 11k aparece una cláusula intransitiva sin que se explicite quién es el participante absolutivo; parece que aquí es el contexto el que indica que se trata de El de la Cabecera del Nharíne, ya que él es quien ha soñado anteriormente. En esta cláusula se establece un nuevo referente como tópico, ó enéque atác acsufá maráma 'los otros que existen por su propia voluntad', y este referente junto con El de la Cabecera del Nharíne son los dos más topicales en las siguientes cláusulas (que no se han incluido aquí). La de la Cabecera del Aóre ya no se vuelve a mencionar hasta mucho después en el discurso y, cuando esto sucede, se hace por medio de una estrategia léxica (Constenla, Castro y Blanco 1993: 69;89-91):

(12) a. Ta-cá nícacáfa i-pu-nhé, y-SUC una.vez 3-estar-MR

"Pero sucedió"

b. ta-cá ní-ni i-p-jírri-nhé únha-cá Aóre Cha Có-nhe, y-SUC esto-COP 3-AP-importunar-MR andar-N Río.Muerte (3)-Cabecera (3)-en-SUST "que estuviera importunando La de la Cabecera del Aóre,"

La de la Cabecera del Aóre vuelve a ser referida en las cláusulas subsiguientes, en las que también se menciona a otra diosa, La que Vela por el Curso Medio del Ucúrinh, en una cláusula. Por lo tanto, El de la Cabecera del Nharíne pierde su posición como uno de los referentes más topicales/accesibles y se tiene que expresar de manera léxica cuando se vuelve a introducir en el discurso en 13b (Constenla, Castro y Blanco 1993: 69-70;107-111). Después de la reintroducción, los dos referentes más accesibles son El de la Cabecera del Nharíne y La de la Cabecera del Aóre, lo cual se puede observar en 13c-e, donde ambos son expresados de manera no explícita.

(13) a. Ta-cá ninhá-fa i-tiní i-p-jirri-nhé unhé-unhé, y-SUC así-ENF 3-por 3-AP-importunar-MR andar-IT

"Y así estuvo (La de la Cabecera del Aóre) importunando por ello,"

b. táni i-quí Nharíne Cha Có-nhe

y 3-decir Río.Venado (3)-Cabecera en-SUST

"pero El de la Cabecera del Nharíne dijo"

c. ótacá rri-cuá-nhe, cuando (3)-3erg-ver-MR

"cuando lo vio," 


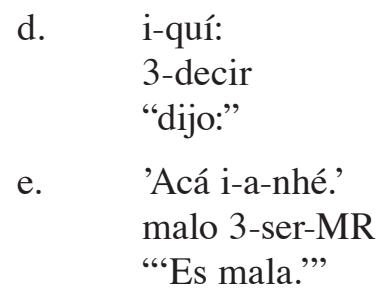

Ahora bien, hemos visto cómo el proceso de cambios de topicalidad entre los referentes se lleva a cabo por medio de sintagmas nominales completos, y que este es el principio básico en cuanto al uso de este tipo de estrategia anafórica. Sin embargo, todos los referentes tomados en cuenta hasta ahora son dioses, es decir, de la misma categoría semántica. En 11c aparece un referente que todavía no hemos mencionado: $u$ ' 'la casa'. Se introduce por medio de una estrategia léxica igual que los demás referentes, ya que no ha sido mencionado anteriormente, pero no es considerado como posible referente de los prefijos de la tercera persona en las cláusulas subsiguientes. Esto parece deberse a su bajo nivel de animidad: una casa difícilmente puede ser el participante ergativo de un evento verbal.

Veamos un ejemplo (Constenla, Castro y Blanco 1993: 72;191-198) en el que un dios le lleva sangre al Sol, quien aparece como un ser animado: ${ }^{5}$

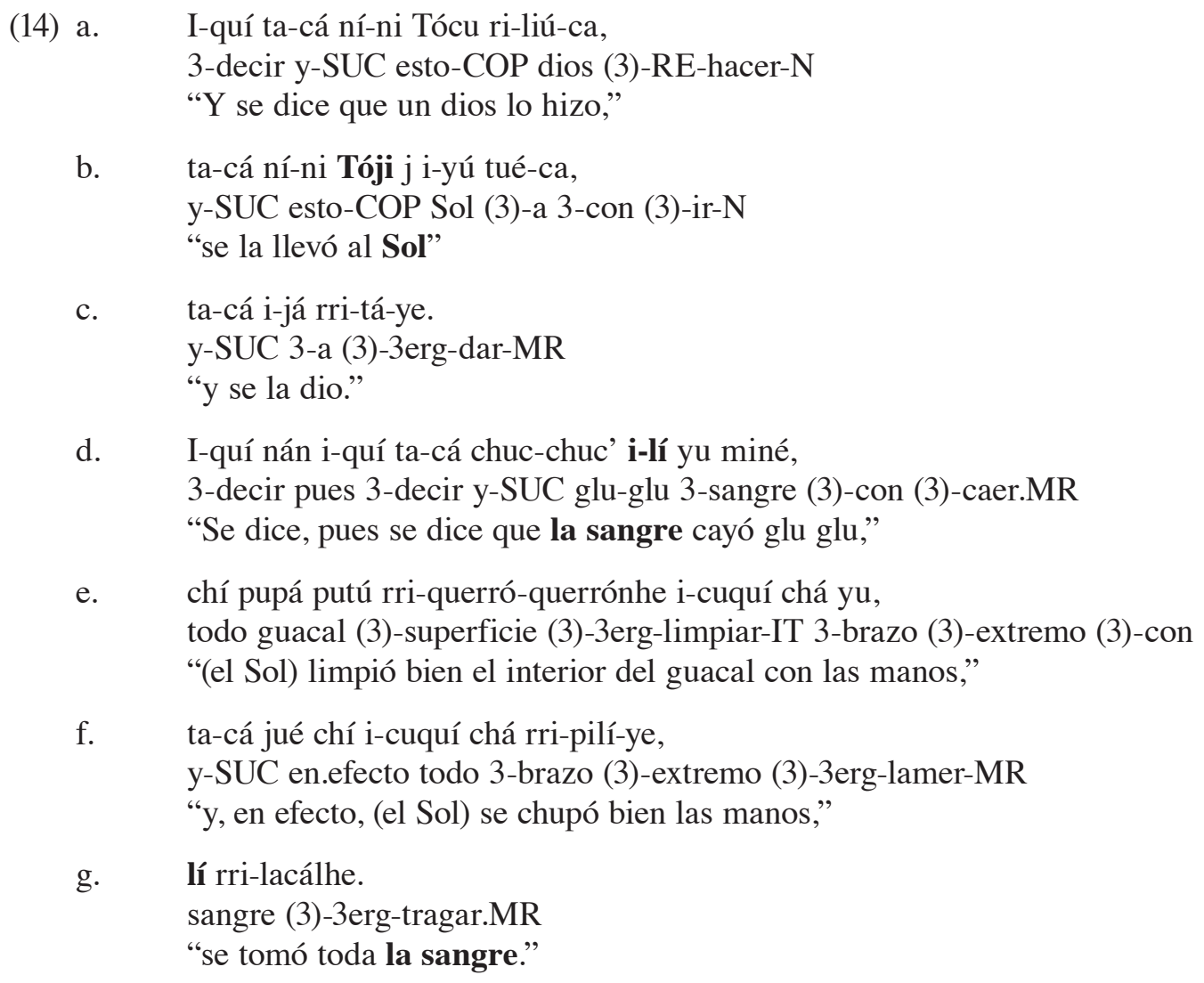

En 14d, la sangre se expresa de manera léxica, probablemente debido a que, en teoría, el Sol podría ser el referente que cae. La cláusula más interesante es 14e: el participante 
ergativo aquí es el Sol, que se expresa de manera no explícita, aunque el único participante de la cláusula anterior fue la sangre. Además, la última referencia al Sol fue en 14c (donde también hay una referencia al dios), por medio de un alomorfo cero del prefijo de la tercera persona en un sintagma posposicional. De todos modos, el hablante no considera necesario explicitar que el participante ergativo en $14 \mathrm{e}$ es el Sol, aunque tanto el dios como la sangre han aparecido con roles sintácticos típicamente más topicales que el Sol en las cláusulas previas. Por ello, parece evidente que la principal función de los sintagmas nominales completos es desambiguar el referente y que el contexto también cumple un papel muy importante en la desambiguación. Por el contexto, el oyente puede enterarse de que el Sol tiene que ser el que chupa bien el interior del guacal, ya que fue a él a quien el dios llevó la sangre. En 14g vuelve a aparecer una referencia de la sangre mediante un sustantivo, probablemente para especificar que lo que se tragó el Sol no fue ni el guacal ni sus manos, referentes mencionados más recientemente que la sangre y, por lo tanto, más topicales.

También se emplea una estrategia léxica cuando una serie de cláusulas incluyen los mismos participantes, pero cuyos roles sintácticos cambian. Esto se aprecia en 15 (Constenla, Castro y Blanco 1993: 81;485-487):

(15) a. ta-cá ní-ni i-j i-p-teléle-cá y-SUC esto-COP 3-sobre 3-AP-pisotear-N "y lo pisoteó"

b. ta-cá amí ní yu juarí-nhe lucúluc. y-SUC de.nuevo este con (3)-vomitar-MR sapo "y vomitó de nuevo el sapo."

c. Ta-cá ní-ni naí-t i-quí curíjuri: y-SUC esto-COP aquel-ERG 3-decir mujer "Y le dijo la mujer:"

d. 'Má-pe jué enéque yu mi-tué cué pal?' INT-NEG en.efecto otro (3)-con 2-ir fuego pedazo "'NNo te llevas en verdad nada de fuego?"

e. Ta-cá lucúlucú-t i-quí, y-SUC sapo-ERG 3-decir "Y el sapo le dijo,"

En 15a, la mujer es el actante absolutivo, mientras que el sapo es oblicuo, por ser referido en el sintagma posposicional. En 15b, en cambio, el sapo es el actante absolutivo, lo cual se indica mediante un sustantivo. En 15c aparece un verbo transitivo; el contexto no aporta información sobre cuál de los dos participantes más topicales es el absolutivo y cuál es el ergativo, por lo que se utiliza una estrategia léxica para expresar el actante ergativo, la mujer. Al igual que en casi todos los demás casos en los que el participante ergativo es explícito, la cláusula es orientada al ergativo. Como el sapo es el otro participante altamente topical, se da por hecho que este es el actante absolutivo. En 15e, los roles vuelven a cambiar, lo cual que se expresa de la misma manera que en 15c: codificando el participante ergativo de manera léxica.

Como se ha podido observar, los elementos léxicos se emplean principalmente para evitar ambigüedad en cuanto al referente, por lo que suelen utilizarse cuando aparece un 
referente que no ha sido de los más topicales en las últimas cláusulas y cuando los roles sintácticos de los tópicos cambian. Este uso se puede considerar el básico, por lo que trataremos todas las excepciones a este esquema como casos de sobre-codificación o sub-codificación.

\subsubsection{Sub-codificación del referente}

Algunas pocas veces, los roles sintácticos de los participantes cambian sin que esto se indique explícitamente, lo cual puede producir ambigüedad. No aparecen muchos ejemplos de este tipo en el corpus, pues se tiende a marcar explícitamente cada vez que los referentes cambian o cuando sus roles sintácticos son invertidos, por medio de expresiones léxicas de los referentes en cuestión. Un ejemplo de sub-codificación en este sentido es el ejemplo 16 (Constenla, Castro y Blanco 1993: 97;1050-1059). Los dos participantes más topicales en las cláusulas precedentes son La que Vela por el Curso Medio del Ucúrinh (una diosa) y una persona, de los cuales la diosa es la más topical, ya que, en las cláusulas anteriores, es el participante ergativo de las cláusulas transitivas y el absolutivo de las intransitivas. En 16c, sin embargo, se entiende por el contexto discursivo que el participante absolutivo de la cláusula intransitiva aquí es la persona, al igual que es el ergativo en 16d y 16f. En 16h, los roles cambian de nuevo, y La que Vela por el Curso Medio del Ucúrinh se convierte en el participante ergativo de nuevo. En los textos analizados, tales cambios de roles sintácticos que se ven en 16c y 16h normalmente se indican por medio de sintagmas nominales, pero, como se puede observar, el contexto a veces se considera información suficiente.

(16) a. i-quí chiúnhetá, ta-cá rri-catá-nhe.

3-decir al.rato y-SUC (3)-3erg-agarrar-MR

"y se dice que, pasado un momento, agarró a una."

b. Nán i-quí pá rri-catá-nhe, pues 3-decir ya (3)-3erg-agarrar-MR,

c. i-quí nán i-quí, ta-cá jo có-fa i-jó-ye, 3-decir pues 3-decir y-SUC (3)-cara (3)-en-ENF 3-llorar-MR

"se dice, pues se dice que lloró por la situación en que estaba,"

d. i-rri-quí:

3-3erg-decir

"le dijo:"

e. ¿ ¿Inánheyú ninhá toí na-rrp-jó-ye?'

por.qué así 1E 1E-2erg-hacer-MR

“¿Por qué nos han hecho esto?"”

f. I-rri-quí:

3-3erg-decir

"Le dijo:"

g. 'Mári mi-cuá toí na-nhe-rr.'

he.aquí 2-por 1E 1E-ser-MR-HA

"'He aquí lo que nos ha sucedido por obra de ustedes."

h. Ta-cá ní-ni i-yú tué-ca né Tócu carrá co,

y-SUC este-COP 3-con (3)-ir-N allá dios (3)-lugar (3)-en

"Y se lo llevó allá, adonde el otro dios," 


\subsubsection{Sobre-codificación del referente}

Los análisis indican que, en líneas generales, los sintagmas nominales completos se emplean cuando es necesario especificar semánticamente al referente para evitar una posible ambigüedad y cuando el referente no es conocido para el oyente. No obstante, en el corpus hay algunos casos de sobre-codificación, es decir, casos en los que se emplea una estrategia léxica aunque una estrategia no explícita no produciría ambigüedad. Un ejemplo muy claro de sobrecodificación se ve en 17 (Constenla, Castro y Blanco 1993: 74;277-282), tomado del texto 2, donde el referente 'tus pavones' se expresa de manera léxica en todas las cláusulas:

(17) a. 'Ninhá-fa-tó pó mi-túfi anh, así-ENF-F 2 2-pavón (3)-ser

“"Así serán tus pavones,"

b. épe-tó me mi-túfi maráma ri-anh.

NEG-F NEG 2-pavón PL (3)-bañar

"no se bañarán tus pavones."

c. Acá-fa-tó mi-túfi maráma purú új-e punh cúta cuinhca óra inh.

Mal-ENF-F 2-pavón PL (3)-cuerpo (3)-oler-MR estar murciélago (3)-ala DIM

(3)-como "El cuerpo de tus pavones olerá mal como alita de murciélago."

d. Épe-tó me mi-túfi maráma ri-anh.

NEG-F NEG 2-pavón PL (3)-bañar

"No se bañarán tus pavones."

e. Quinhílhi-quinhílhi-fá-to mi-túfi maráma unh.

con.la.cara.ajada-con.la.cara.ajada-ENF-F 2-pavón PL (3)-andar

"Andarán con el rostro ajado tus pavones."

f. Épe-tó me mi-túfi maráma-tí cajúli chía.'

NEG-F NEG 2-pavón PL-ERG chocolate (3)-beber

“Tus pavones no beberán chocolate."”

En primer lugar, tal uso de sintagmas nominales no es necesario para especificar el referente y, en segundo lugar, tampoco constituye un cambio semántico de las cláusulas. Resulta natural suponer que se trata de un recurso retórico, del tipo que van Dijk (1990: 50) describe como una transformación utilizada por el hablante "para intensificar la organización y de ahí la atención, el almacenamiento y la recuperación de la información del texto por parte del oyente". Esta definición implica una función de marcación de topicalidad, lo cual parece plausible dada la alta topicalidad que exhibe el referente repetido. También parece probable que este recurso esté relacionado con el género literario que se está analizando, en el que la repetición de otros tipos de estructuras, sobre todo los eventos verbales, es un fenómeno frecuentemente observado, y que no se utilice en situaciones comunicativas menos formales. Esta última afirmación, por supuesto, tendría que comprobarse mediante análisis de otras clases de comunicación lingüística en malecu.

Otro ejemplo de sobre-codificación de un referente se presenta a continuación (Constenla, Castro y Blanco 1993: 91;823-831), en el que el referente sobre-codificado es tafá 'el jaguar': 
(18) a. ta-cá naí coné i-lhá maráma tafá ri-uchí-ca, y-SUC aquel (3)-de 3-sobre PL jaguar (3)-RE-abalanzar-N "y de ellos se les abalanzó el jaguar,"

b. ta-cá ní-ni tafá-t i-cué-cué-ca maráma. y-SUC esto-COP jaguar-ERG 3-matar-IT-N PL "y el jaguar los fue matando."

c. Ta-cá ami enéque rri-úji-nhé, y-SUC de.nuevo otro (3)-3erg-enviar-MR "Y envió a otros,"

d. i-rrí-quí:

3-3erg-decir

"les dijo:"

e. 'I-rrp-té-cú.'

3-2erg-ALEJ-coger

"'Id a buscarlos."”

f. Nán i-quí ninhá-fa amí paquéquirrí-fa maírrinhá-nhe maráma rri-lachó-nhe tafá pá.

pues 3-decir así-ENF de.nuevo cuatro-ENF malo-SUST PL (3)-3erg-acabarMR jaguar ya

"Pues se dice que así ya de nuevo atrapó a cuatro malos el jaguar."

g. Tafá tócufá i-lhá maráma pútequí toí-nhe, jaguar AUM 3-sobre PL (3)-salir pasar-MR

"Les salió un gran jaguar,"

h. chí tafá-t i-turé maráme. todo jaguar-ERG 3-exterminar PL.MR

"a todos los mató el jaguar."

i. Tafá-t i-canh maráme. jaguar-ERG 3-comer PL.MR

"El jaguar los devoró."

Dada la importancia del jaguar en este pasaje, la suposición de que la sobrecodificación de referentes es un recurso que se emplea para destacar a ciertos participantes altamente topicales parece muy probable. De hecho, todos los casos de sobre-codificación que se registraron en el corpus son referencias de participantes muy topicales.

\subsection{Uso de pronombres}

En esta sección se va a analizar el uso de los pronombres personales, incluyendo los pronombres demostrativos que funcionan como tales (ní y naí, sarróqui y sárru). Un pronombre personal generalmente no aporta más información semántica que su prefijo verbal correferencial. Por eso, lo que habrá que explicar es qué es lo que provoca el uso de un pronombre frente a un simple prefijo verbal de persona sin otro elemento correferencial. Con 
la finalidad de ofrecer un panorama más completo en cuanto al uso de pronombres, también se incluye un análisis del uso de los pronombres de la primera y la segunda persona, aunque ese tema fue excluido de los análisis cuantitativos.

\subsubsection{Elemento desambiguador}

El análisis cualitativo revela que los pronombres se utilizan frente a las estrategias no explícitas con diferentes funciones. En primer lugar, se usan para evitar ambigüedad en cuanto a referencias de la primera persona, igual que los sintagmas nominales completos para la tercera persona. En las series de prefijos verbales no se distingue entre la primera persona exclusiva del singular y la del plural, pero tal distinción sí existe en la serie de pronombres. El prefijo absolutivo de la primera persona exclusiva es $n a$ - y el de la serie ergativa es $r r a$ - sin distinción entre singular y plural, mientras que en la serie de pronombres sí se marca el número gramatical: ton es singular y toí es plural. Por ello, estos pronombres se pueden utilizar para aclarar el número gramatical del referente. En la mayoría de las apariciones de estos prefijos sin pronombre correferencial, su significado es singular, mientras que se tiende a agregar el pronombre toí cuando el significado es plural, lo cual puede significar que el número gramatical de estos prefijos "por defecto" es singular. Por otro lado, también puede deberse al hecho de que siempre existe la posibilidad de que el referente sea singular (la persona que habla), mientras que en muchos casos no existe la posibilidad de que el referente sea plural, por lo que se tiende a explicitarlo cuando ocurre lo último.

Los ejemplos 19 (Constenla, Castro y Blanco 1993: 89;760) y 20 (Constenla, Castro y Blanco 1993: 72;172) muestran un uso de los prefijos de la primera persona exclusiva, na- y rra-, sin pronombre, con significado singular:

(19) Atí mi-tiní maráma sojé na-rá-arinh-nec.

para 2-por PL hoy 1E-RE-esconder-EXH

"Me ocultaré hoy de ustedes."

(20) ní rra-cú ó malécu lí

este (3)-1Eerg-coger que persona (3)-sangre

"recogeré la sangre de la persona"

En 21 (Constenla, Castro y Blanco 1993: 69;100) y 22 (Constenla, Castro y Blanco 1993: 73;230), el referente es plural, lo cual se explicita mediante el pronombre toí:

(21) Iná-to i-lhá toí-ti mi-coquí cú-ca, cómo-F 3-sobre 1Epl-ERG 2-boca (3)-coger-N

“Cómo podríamos prestarte atención?"

(22) mi-yú-to toí na-tué,

3-con-F 1Epl 1E-ir

"te llevaremos,"

La misma ambigüedad existe con el prefijo $m a-$, que puede expresar tanto la primera persona inclusiva como impersonalidad. Por lo mismo, en muchos casos se utiliza el pronombre tótiqui para indicar que el referente es de primera persona inclusiva. Además, la lengua no posee ningún pronombre impersonal, y parece que, si no se usa el pronombre tótiqui, es fácil 
que el referente se entienda como impersonal. En el ejemplo 23 (Constenla, Castro y Blanco 1993: 113;1657-1658), la primera persona inclusiva se especifica en 23a, mientras que en 23b, donde el verbo se repite, no es necesario volver a especificarlo, dado que la posible ambigüedad ya ha sido eliminada:

(23) a. Atú-ma ní-ti tótiquí ma-quí Tócu. si-COND este-ERG 1I-decir dios "Y si el dios nos hubiera dicho,"

b. ma-rri-quí: 1I-3erg-decir: "nos hubiera dicho"

En cambio, en 24 (Constenla, Castro y Blanco 1993: 113;1666-1667), el hablante considera necesario especificar el referente por medio de un pronombre en las dos cláusulas seguidas porque no se trata de una repetición del mismo evento sino que los verbos son diferentes, y la función sintáctica del referente en cuestión cambia (ergativo en 24a y absolutivo en 24b):

(24) a. Ta-cá epéme tótiqui ní ri-ca-nhé y-SUC NEG 1I este (3)-1Ierg-comer-MR

"Y no comemos"

b. ó ja tótiqui ma-rri-quí-ye tafí-nhe: que (3)-sobre 1I 1I-3erg-decir-FORM dejar-MR "aquellos sobre los que nos dejó dicho:"

\subsubsection{Contraste enfático}

Además de tener una función desambiguadora, los pronombres de la primera y la segunda persona tienden a emplearse para cumplir una función contrastiva. El elemento con el que contrasta puede mencionarse explícitamente, como en el ejemplo 25 (Constenla, Castro y Blanco 1993: 68;59-60), donde los pronombres ton y pó contrastan el uno con el otro. Nótese que los pronombres yo y tú en la traducción al español cumplen exactamente la misma función.

(25) a. Ton-to na-tafinh Nharíne cha co.

1Esg-F 1E-quedar Río.Venado cabecera (3)-en

"Yo permaneceré en la cabecera del Nharíne."

b. Pó-to mi-tué Aóre chá carrá co.

2-F 2-ir Río.Muerte (3)-cabecera (3)-lugar (3)-en

"Tú irás al lugar de la cabecera del Nharíne."

Más frecuentemente, los pronombres se emplean con la función de resaltar su referente para expresar que lo que se dice sobre él lo distingue de los demás. Por ejemplo, en 26 (Constenla, Castro y Blanco 1993: 76;341), el pronombre ní (referido a un colibrí) se emplea con un significado implícito de 'él, contrario a todos los demás (que no pudieron subir al Sol)'. También aquí, el pronombre en la traducción al español, él, se emplea por la misma razón.

(26) Paítafá móniquichíca ní-t i-taqué coló.

tal.vez ojalá este-ERG 3-subir bien

"Ojalá y tal vez él lo suba bien." 
En el ejemplo 27 (Constenla, Castro y Blanco 1993: 92;869-870), ní cumple la misma función, subrayando el hecho de que al jaguar en cuestión no le sucedió lo mismo que a los otros jaguares:

(27) a. Tán i-quí lacáchá-ru ója píte-nhé tafá, pero 3-decir uno-LIM (3)-correr salir-MR jaguar

"Pero se dice que un único jaguar escapó"

b. ta-cá épe iná ní a-nh.

y-SUC NEG cómo este (3)-ser-MR

"y a este no le sucedió así."

En 28 (Constenla, Castro y Blanco 1993: 69;90-93) se emplean pronombres de la tercera persona, sárru y ní, en dos cláusulas seguidas (30d-e) con la misma función: en los dos casos se enfatiza que, contrario a los demás dioses, ella (La de la Cabecera del Aóre) se conducía así y ella no sabía nada.

(28) a. ta-cá ní-ni i-p-jírri-nhé únha-cá Aóre Cha Có-nhe,

y-SUC esto-COP 3-AP-importunar-MR andar-N Río.Muerte (3)-Cabecera

(3)-en-SUST

"y estaba importunando La de la Cabecera del Aóre,"

b. i-rri-quí

3-3erg-decir

"decía:"

c. ta ní ma-lhifíji-c.

(para)-IC este 1I-AP-cambiar-N

"quiero que esto cambie."

d. Sárru ninhá i-a-nhé,

ese así 3-ser-MR

"Ella se conducía así,"

e. puráni epéme ní-ti orróqui uráje,

porque NEG este-ERG cosa (3)-saber.MR

"porque ella no sabía nada,"

La misma estrategia se sigue en otros tipos de sintagmas. En el siguiente ejemplo, se emplea en un sintagma nominal (Constenla, Castro y Blanco 1993: 69;105), donde el pronombre tiene la función de poseedor de túfi 'pavón':

(29) Puráni epéme ní túfi a-nh.

Porque NEG este pavón (3)-ser-MR

"Porque ella no tiene pavones."

\subsubsection{Elemento sustitutivo de sintagmas nominales desplazados}

Los elementos originalmente deícticos que funcionan como pronombre de tercera persona, sobre todo ní, aparecen con mayor frecuencia como elementos sustitutivos correferenciales con sintagmas nominales desplazados a la derecha del verbo, una construcción 
que se analizará con más detalle adelante. En estos casos, el pronombre funciona como una referencia catafórica que le indica al oyente que el referente se explicitará más adelante, normalmente en la misma cláusula, como en 30 (Constenla, Castro y Blanco 1993: 101;1225).

(30) Nocófa ní quí Aóre Cha Có-nhe

en.verdad este decir Río.Muerte (3)-Cabecera (3)-en-SUST

"En verdad decía La de la Cabecera del Aóre"

A veces, la explicitación se realiza en otra cláusula, como en el ejemplo 31 (Constenla, Castro y Blanco 1993: 98;1103-1104). De todos modos, el pronombre ní le indica al oyente que es probable que el referente se explicite más adelante en el discurso.

(31) a. Ní-to rr-p-jué, este-F (3)-2erg-hacer

"Los harás,"

b. mi-túfi yú-to mi-quijérri

2-pavón (3)-con-F 2-despertar

"crearás a tus pavones."

\section{Conclusiones}

A partir de nuestro análisis, encontramos que, de acuerdo con las teorías de Givón (1983, 2001a, 2001b) y Chafe (1994), la estrategia empleada en malecu para expresar las referencias anafóricas depende de la identificabilidad del referente. Empleando los términos del funcionalismo, podemos afirmar que la estrategia utilizada para expresar un referente refleja icónicamente su identificabilidad. Según la necesidad de explicitar el referente, el hablante lo expresa mediante una de las dos siguientes estrategias:

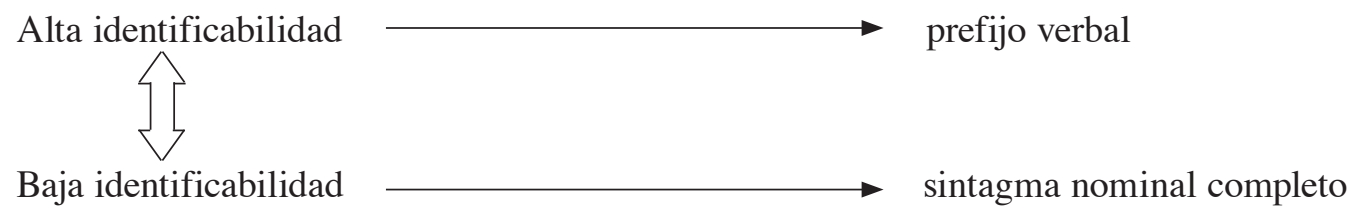

Figura 1. La relación entre la identificabilidad del referente y la estrategia empleada para expresarlo en malecu

La distinción entre estas estrategias consiste en el grado de especificidad semántica que expresan: un referente menos identificable requiere una estrategia semánticamente más específica para ser identificado. En los análisis, las construcciones de prefijo con pronombre correferencial fueron tratadas como una tercera estrategia, pero los resultados indican que, cuando el referente es de tercera persona, el uso de un pronombre correferencial con el prefijo verbal frente al uso de un prefijo verbal sin elemento correferencial no es determinado por la identificabilidad del referente. Más adelante nos referimos al asunto.

El análisis cualitativo reveló que la principal razón por la que surge la necesidad de hacer la referencia anafórica semánticamente más específica en malecu es la posible ambigüedad, es decir, la interferencia de otros participantes que podrían ser el referente. La 
distancia referencial o anafórica, propuesta por Givón (1983) como otro factor determinante para la dificultad de identificar un referente, parece influir menos en la elección de la estrategia anafórica. De hecho, en el corpus no se observa ningún ejemplo del uso de una estrategia léxica únicamente como consecuencia de que la distancia anafórica sea larga, sin la interferencia de otros posibles referentes.

Para introducir nuevos participantes en el discurso, se utilizan, casi sin excepciones, elementos léxicos, lo cual se debe a que estos participantes no son accesibles. Lo que provoca que un participante ya introducido se vuelva a expresar de manera léxica parece ser siempre la interferencia de otros posibles referentes. Está claro que es muy fácil que la estrategia menos explícita en esta lengua, por contener tan poca información semántica, cree ambigüedad en cuanto al referente, por lo que solo los referentes muy continuos (activos) son expresados de esa manera. Cuando la distancia anafórica es mayor, es más probable que hayan aparecido posibles referentes desde la última referencia del participante. Por ello, la distancia anafórica promedio de las construcciones léxicas termina siendo mayor que la de las construcciones no léxicas, pero este solo parece ser un efecto secundario implicado por la función principal de la estrategia léxica: la desambiguación.

La afirmación de Chafe (1994: 79) de que el número de referentes que pueden estar activos al mismo tiempo es relativamente bajo y que tienen que ser mencionados continuamente para seguir en estado activo parece describir bien los hechos encontrados en la presente investigación, porque, cuando no son mencionados continuamente, aparecen otros posibles referentes que pueden crear ambigüedad. Es preciso señalar que el contexto así como las propiedades semánticas de los participantes son factores importantes a la hora de identificar el referente de una estrategia no léxica.

Aunque la estrategia léxica se emplea casi solo cuando es necesario especificar el referente, también se usa en algunos casos para codificar participantes altamente topicales y accesibles, lo cual es de suponer que constituye un recurso retórico propio del género literario analizado en la presente investigación. Recuérdese que las narraciones tradicionales presentan una serie de rasgos que no aparecen en otras clases de comunicación lingüística en malecu.

Los elementos originalmente deícticos que funcionan como pronombres de tercera persona, cuando aparecen sin un elemento léxico correferencial en la misma cláusula o en una cláusula inmediatamente seguida, se utilizan sobre todo con una función contrastiva para enfatizar que su referente se distingue de otros. Estos elementos también se emplean con una función principalmente catafórica, como pronombres sustitutivos, indicando que el referente se explicitará mediante una estrategia léxica al final de la cláusula o en una de las cláusulas siguientes.

Los llamados pronombres personales de primera y segunda persona también se pueden emplear con una función contrastiva. Además, a diferencia de los pronombres de la tercera persona, pueden utilizarse para especificar semánticamente al referente, pues algunos incluyen más información semántica que los prefijos verbales: en la serie de pronombres se distingue entre el singular y el plural de la primera persona exclusiva, y el pronombre de primera persona inclusiva sirve para eliminar la posible interpretación del prefijo correspondiente como una referencia impersonal.

La limitación claramente más importante de esta investigación es el hecho de que el corpus solo consiste en narraciones tradicionales. Esta clase de comunicación oral, al ser un género del arte verbal tradicional del pueblo malecu, se distingue considerablemente de otros 
géneros discursivos o formas en las que se emplea la lengua. La alta frecuencia de rasgos como la repetición y el paralelismo seguramente influye en los resultados de la investigación. Resulta imprescindible estudiar otras clases de comunicación en malecu, sobre todo géneros no literarios, para llegar a conocer de modo más completo el sistema de mantenimiento de las referencias de los participantes discursivos en esta lengua.

\section{Abreviaturas}

Las abreviaturas utilizadas en el presente trabajo están basadas en las de Constenla (1998).

- $\quad$ Linde de morfema

- Separa significados del español que en conjunto traducen un solo elemento malecu

$\varnothing \quad$ Alomorfo cero

(X) El morfema X no se manifiesta fónicamente (es un alomorfo cero)

1E Primera persona exclusiva, absolutivo

1Eerg Primera persona exclusiva, ergativo

1Esg Primera persona exclusiva, singular

1Epl Primera persona exclusiva, plural

1I Primera persona inclusiva, absolutivo; o pronombre de primera persona inclusiva

1Ierg Primera persona inclusiva, ergativo

2 Segunda persona, absolutivo; o pronombre de segunda persona

2erg Segunda persona, ergativo

3 Tercera persona, absolutivo

3erg Tercera persona, ergativo

AUM Aumentativo

ALEJ Alejamiento

COND Condicional

COP Cópula

ENF Enfático

ERG Posposición ergativa

EXH Exhortativo

F Futuro mediato

FORM Formativo de formas verbales complejas

HA Elemento reforzador del elemento mári 'he aquí'

IC Sucesión inmediata o contemporaneidad

INT Interrogación

IT Iterativo

LIM Limitativo

MR Modo real

N Marcador de atemporalidad

NEG Negación

PL Plural

SUC Marcador de sucesión en el tiempo

SUST Sustantivizador 


\section{Notas}

1. La transcripción del malecu se hace siguiendo la ortografía práctica empleada en Constenla, Castro y Blanco (1993) y en Constenla (1998).

2. El concepto de "elementos detalladores" lo toma Constenla (1998) de la tagmemática, una teoría lingüística desarrollada por Kenneth L. Pike (Crystal 2011).

3. Las referencias de los participantes ergativos en las llamadas cláusulas orientadas al ergativo constituyen una excepción, ya que no presentan prefijo verbal, sino solamente un pronombre o un sintagma nominal completo en una cláusula posposicional. Estas referencias fueron agrupadas junto con las del segundo y del tercer tipo, respectivamente.

4. La de la Cabecera del Aóre y El de la Cabecera del Nharíne son dos de los dioses de la religión tradicional malecu.

5. Según la religión tradicional malecu, el Sol es un ser de figura humana que se identifica como el dios de los blancos (Constenla, Castro y Blanco 1993: 48).

\section{Bibliografía}

Álvarez Navarro, Emilia M. et al. 1979. Análisis fonológicos y gramática generativotransformacional del maleku (guatuso). Trabajo final de graduación: Universidad de Costa Rica.

Ariel, Mira. 1990. Accessing noun phrase antecedents. Nueva York: Routeledge.

Bosque y Demonte (Eds.). 1999. Gramática descriptiva de la lengua española. Madrid: Escarpe.

Brucart, José María. 1999. “La elipsis”. En: Bosque y Demonte (Eds.). 2787-2866.

Chafe, Wallace. 1994. Discourse, consciousness, and time: The flow and displacement of conscious experience in speaking and writing. Chicago: The University of Chicago Press.

Constenla Umaña, Adolfo. 1975. La lengua guatusa: fonología, gramática y léxico. Tesis de licenciatura: Universidad de Costa Rica.

1986. "La función de una alternativa gramatical guatusa en el discurso narrativo tradicional”. En: Barrantes et al. (Comps.). 119-128.

1998. Gramática de la lengua guatusa. Heredia: Editorial de la Universidad Nacional.

2008. "Estado actual de la subclasificación de las lenguas chibchenses y de la reconstrucción fonológica y gramatical del protochibchense". Estudios de lingüística Chibcha. 27: 117-135.

Constenla Umaña, Eustaquio Castro C. y Antonio Blanco R. 1993. Laca majifijica. La transformación de la tierra. San José: Editorial de la Universidad de Costa Rica.

Crystal, David. 2011. Dictionary of linguistics and phonetics. Oxford: Wiley-Blackwell.

Givón, Talmy. 1983. Topic continuity in discourse: A quantitative cross language study. Amsterdam: John Benjamins.

2001a. Syntax. Vol. I. Amsterdam: John Benjamins.

2001b. Syntax. Vol. II. Amsterdam: John Benjamins. 
Jara Murillo, Carla Victoria. 2003. "Codificación de participantes en una narración bribri”. Estudios de Lingüística Chibcha. 22: 33-60.

Luján, Marta. 1999. "Expresión y omisión del pronombre personal”. En: Bosque y Demonte (Eds.). 1275-1316.

Payne, Thomas. 1997. Describing morphosyntax. Cambridge: Cambridge University Press.

Quesada, Juan Diego. 2007. The Chibchan languages. Cartago: Editorial Tecnológica de Costa Rica.

Salas, Álvaro. 1990. Análisis del discurso de la narrativa boruca. Tesis de maestría: Universidad de Costa Rica.

Van Dijk, Teun A. 1990. La noticia como discurso. Barcelona: Paidós Comunicación. 